\title{
Synthesis of cross-linked polyurethane elastomers with the inclusion of polar-aromatic moieties (BA, PNBA and 3, 5-DNBA): Electrical and thermo-mechanical properties analysis
}

\author{
Manauwar Ali Ansari ${ }^{1}$ D Patcharapon Somdee ${ }^{1} \cdot$ Kálmán Marossy $^{1,2}$
}

Received: 9 October 2020 / Accepted: 18 April 2021 / Published online: 26 April 2021

(c) The Author(s) 2021

\begin{abstract}
In this work, we used the design strategy "doped nonpolar polymers" and synthesized the polyurethane elastomers (PUEs) by doping with highly polar aromatic molecules such as benzoic acid (BA), 4(para)-nitro-benzoic acid (PNBA), and 3, 5-dinitro-benzoic acid (3, 5-DNBA) by using the solution casting method. The effect of each molecule in three different weight percentages $2 \%, 4 \%$, and $6 \%$ on electrical and thermo-mechanical properties of the material has studied. Experiments were carried out to determine electrical properties such as DC volume resistivity, dielectric constant, and loss factor. DMA and DSC measurements were done to assess thermo-mechanical properties. Also, thermal conductivity measurement was carried out and a strong nitro group and doping percentage dependent results have been observed. A comparative analysis of the effect on the said properties was done among the doped and undoped PUEs.
\end{abstract}

Keywords Polyurethane elastomers · Polar-aromatic molecules $\cdot$ Doping $\cdot$ Electrical $\cdot$ Thermo-mechanical property

\section{Introduction}

Polyurethane is a class of polymer that has a wide range of physio-chemical properties. Its unique properties make it useful in different fields such as foams, coatings and adhesives industry, bio-medical sciences, plastic industry, and thermoplastic elastomers, etc. [1-3]. Apart from these, it has some disadvantages too, such as non-polarity, low mechanical strength, and low thermal stability [1]. To compensate for these drawbacks material scientists have started synthesizing new composite materials revolutionizing the present material industry. Polymer composites combine both the properties of a polymer and the properties of the filler. For decades, different types of moieties are used as a filler to ameliorate some of the limitations of a polymer to increase their applications. The usage of the polar molecules in a non-polar polymer not only led to high piezoelectricity but also affect the physical and electrical properties which had

Manauwar Ali Ansari

maansarivce@gmail.com

1 Institute of Ceramic and Polymer Engineering, University of Miskolc, 3515 Miskolc, Hungary

2 BorsodChem Zrt, 3702 Kazincbarcika, Hungary replaced the conventional ceramic-based piezoelectric materials [4-10]. Some piezoelectric polymers like cellulose and their derivative, polyurethanes (PU), polyimides (PI), polylactic acid (PLA), polyvinylidene fluoride (PVDF) and its copolymers, etc. have wide applications to many, energyrelated systems [11-15].

In spite of different figures of merit, the polar nonlinear optical (NLO) materials have some similar demands and somehow similar design schemes. For example, doping a nonpolar polymer with a polar compound has yielded considerable success, allowing the optimization of the dopant for ideal optical properties and the optimization of the polymer for easy processing. Complex chromophore molecules are dispersed in nonpolar polymers such as poly (methyl methacrylate) (PMMA) and poled to produce axial alignment $[11,20-22,26]$.

Hitherto, many researchers have demonstrated and found that doping a nonpolar polymer with polar dopants is a highly general strategy and has the potential to lead the materials with considerably higher piezoelectric responses, thermal stability, high-performance NLO materials, and also impact on electrical properties [4, 10, 16-25]. One of the most important classes of polymer for such application is polyurethane. Recently, Moody et al. reported $\mathrm{d}_{33}$ piezo-coefficients approx. $244 \pm 30 \mathrm{pCN}^{-1}$ for flexible 
piezoelectric PU foams [10]. More recently, Petroff et al. used the same strategy and created polar molecules doped polydimethylsiloxane (PDMS) foams and measured the electrical and mechanical properties and by tuning these properties they achieved a maximum $\mathrm{d}_{33}$ piezo-coefficients about $153 \mathrm{pCN}^{-1}$ [4]. Furthermore, many researchers showed that the inclusion of polar molecules in polyurethane can create either high piezoelectricity or NLO materials [27-41]. We motivated by reviewing the previous works to do further experiments to observe the effect of polar moieties on other properties of polyurethane.

In this work, we used the strategy of the doped nonpolar polymer and synthesized polyurethane elastomers by doping with highly polar aromatic molecules such as benzoic acid (BA), 4(p)-nitrobenzoic acid (PNBA), and 3, 5-dinitrobenzoic acid (DNBA) via solution casting method. The effect of each molecule in three different weight percentages $(2 \%, 4 \%$, and $6 \%)$ on the electrical properties such as dielectric constant, loss factor, and DC volume resistivity and thermo-mechanical properties using DSC, DMA, and thermal conductivity of the material has been studied. A wide range of applications is therefore accessible through further investigation and optimization.

\section{Materials and method}

\section{Polyurethane precursors}

Part A: CARADOL MC28-02 is the activated propylene oxide and ethylene oxide-based polyether polyol was purchased from Shell Chemicals. ALCUPOL D0411 or PPG 400 from Repsol is a Polypropylene Glycol. Chain extender MEG (Mono Ethylene Glycol) or Ethylene Glycol were purchased from VWR. Moisture Scavenger (FINMASORB 430PR) molecular sieve pastes were used. DABCO 33-LV (33\% triethylenediamine dissolved in $67 \%$ dipropylene glycol) by Evonik was used as a Catalyst and in the synthesis of pre-polyol and curing of polyurethanes. Benzoic Acid, 4(p)-nitro-benzoic acid and 3, 5-di-nitro-benzoic acid supplied by Reanal, Budapest, Hungary used as doping moieties or as fillers in the PU.

Part B: ONGRONAT XP 1117 (Mixture of MDI mixed isomers and polymeric MDI) was arranged from BorsodChem Zrt. and used as isocyanate part. All ingredients for PUE synthesis are listed in Table 1.

\section{Synthesis method (Solution casting)}

The procedure of preparation of PU elastomers is schematically shown below in Fig. 1. First, we prepare a solution of all properly weighed chemicals of PART-A such as polyols, mono ethylene glycol, FINMASORB, DABCO, etc. Fillers/ additives/ doping agents can be added to this solution if necessary. After proper shear stirring, wait for 10-15 min to avoid air bubbles. Then, pour the as-prepared solution (PART-A) in a specified amount into MDI (PART-B). In this step, a quick reaction is started between isocyanate and polyols. After quick shear stirring of the final solution for $10 \mathrm{~s}$, we poured the final solution (PART-A + PART-B) into preheated $\left(50{ }^{\circ} \mathrm{C}\right)$ mold and after waiting for approximately $60 \mathrm{~min}$ for curing finally remove the cured sample of $1 \mathrm{~mm}-4 \mathrm{~mm}$ thickness.

\section{Results and discussion}

\section{Effect of doping on electrical properties}

\section{Dielectric constant and Loss factor}

Radiometer-Copenhagen Type- CMB 1d No.110033 was used for dielectric properties measurement. This instrument based on the Schering bridge method. The measurement specimen was taken from a $1 \mathrm{~mm}$ thick sample sheet. The graphite spray (GRAPHIT 33) was used for making the
Table 1 Ingredients of polyurethane elastomers

\begin{tabular}{lll}
\hline Description & Trade name & Mass/g \\
\hline Polyether Polyol & Caradol MC28-02 & 10 \\
Polypropylene glycol (PPG-400) & ALCUPOL D4011 & 5 \\
Monoethylene glycol & MEG & 10 \\
Catalyst & Dabco 33-LV & 0.3 \\
Moisture scavenger & Finmasorb 430 PR & 5 \\
4,4'-Diphenylmethane diisocyanate (MDI) & ONGRONAT XP 1117 & $29.92-30.60^{(\text {a) }}$ \\
Benzoic Acid & - & $2,4,6$ \\
4(para)-nitro-benzoic acid & - & $2,4,6$ \\
3, 5- din-nitro-benzoic acid & - & $2,4,6$ \\
\hline
\end{tabular}

(a) Varying with the other ingredients to keep the content of $\mathrm{NCO}$ : $\mathrm{OH}$ ratio and these values are for a total $100 \mathrm{~g}$ of the system mass 


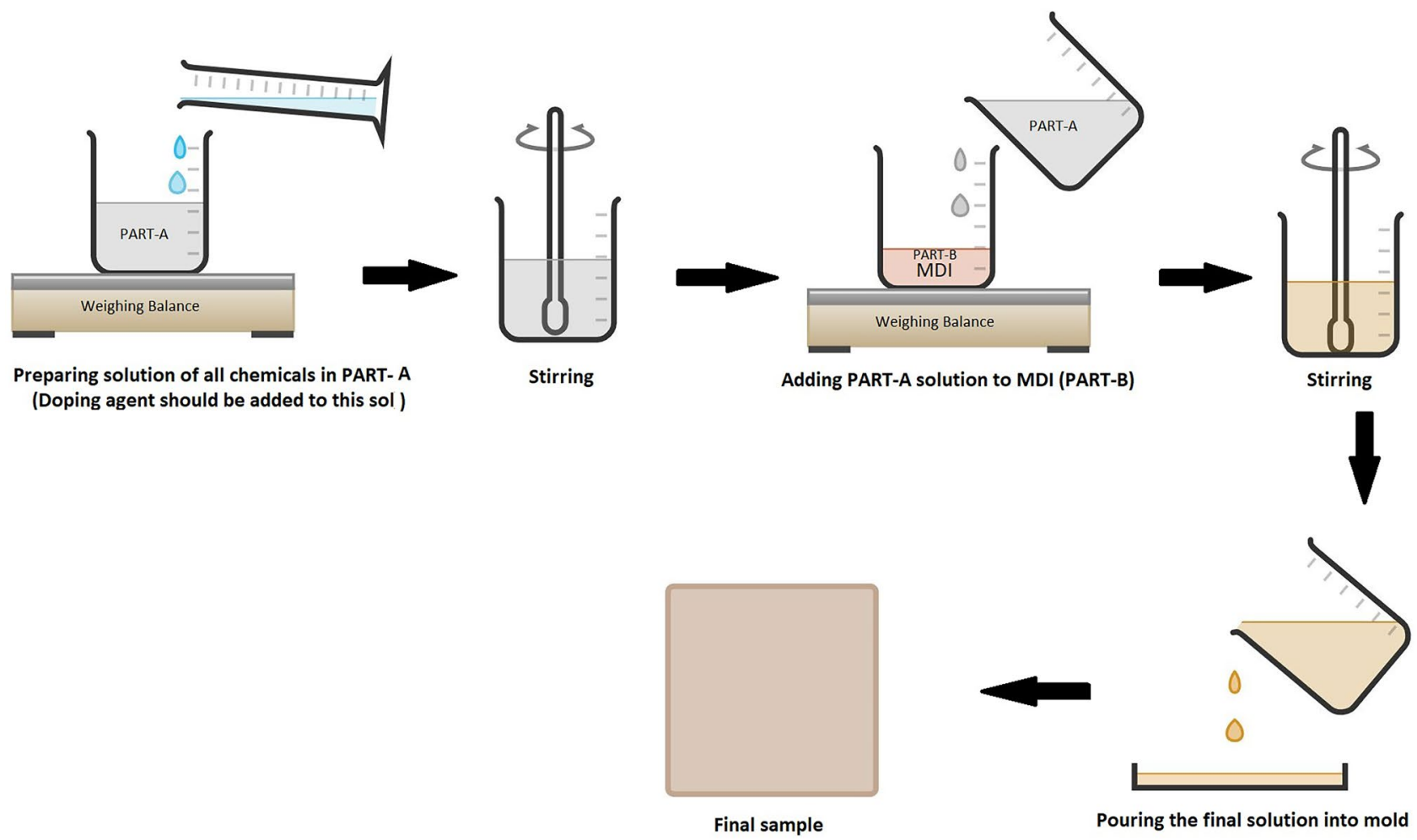

Fig. 1 Schematic procedure of synthesis of pure and doped PUEs sample

electrode contacts. The electrode surface area of the sample was $11.33 \mathrm{~cm}^{2}$. The measurement was taken at room temperature of $23^{\circ} \mathrm{C}$ and the applied $\mathrm{AC}$ input voltage was $63 \mathrm{~V}$ at a frequency of $1 \mathrm{kHz}$. The measurement results are tabulated below in Table 2. The plot of Dielectric constant $\left(\varepsilon_{\mathrm{r}}\right)$ and loss factor (D) with percentage doping content is shown in Fig. 2(a) and (b), respectively. It is observed that dielectric constant of pure PU is less than the poled ones because the undoped (pure) PU elastomers is a nonpolar insulator and have only electronic polarization. By the inclusion of aromatic polar moieties, the dielectric constant increased as compare to pure PU elastomer. This is due to the contribution of dipole polarization (or orientation polarization) in addition to electronic polarization. This can be explained by increasing the doping percentage (wt. \%) of each type in the system the dielectric constant increases due to an increase in the mobility of polar groups and hence mobile groups which contributes more orientation
Table 2 Results of dielectric measurement of pure and doped PUE samples of $1 \mathrm{~mm}$ thick specimen

\begin{tabular}{llllr}
\hline Sample Name & $\begin{array}{l}\text { Capacitance } \\
(\mathrm{C}, \mathrm{pF})\end{array}$ & $\begin{array}{l}\text { Loss factor } \\
(\mathrm{D})\end{array}$ & $\begin{array}{l}\text { Permittivity } \\
\left(\varepsilon, \mathrm{pFm}^{-1}\right)\end{array}$ & $\begin{array}{l}\text { Dielectric constant } \\
\left(\varepsilon_{\mathrm{r}}\right)\end{array}$ \\
\hline Pure PU & 55.15 & 0.0452 & 48.666 & $5.499 \pm 0.601$ \\
PU + 2\% BA & 59.22 & 0.0476 & 54.878 & $6.201 \pm 0.101$ \\
PU +4\% BA & 58.14 & 0.0515 & 51.312 & $5.798 \pm 0.302$ \\
PU +6\% BA & 63.20 & 0.0518 & 55.772 & $6.302 \pm 0.202$ \\
PU + 2\% PNBA & 65.76 & 0.0593 & 57.454 & $6.492 \pm 0.226$ \\
PU + 4\% PNBA & 66.73 & 0.0997 & 58.887 & $6.654 \pm 0.064$ \\
PU +6\% PNBA & 68.90 & 0.112 & 62.020 & $7.008 \pm 0.290$ \\
PU + 2\% DNBA & 69.26 & 0.1 & 59.295 & $6.7 \pm 0.241$ \\
PU + 4\% DNBA & 66.60 & 0.112 & 60.542 & $6.841 \pm 0.100$ \\
PU +6\% DNBA & 71.60 & 0.112 & 64.454 & $7.283 \pm 0.342$ \\
\hline
\end{tabular}


Fig. 2 (a) and (b) Dielectric constant and loss factor vs. percentage of doping moieties
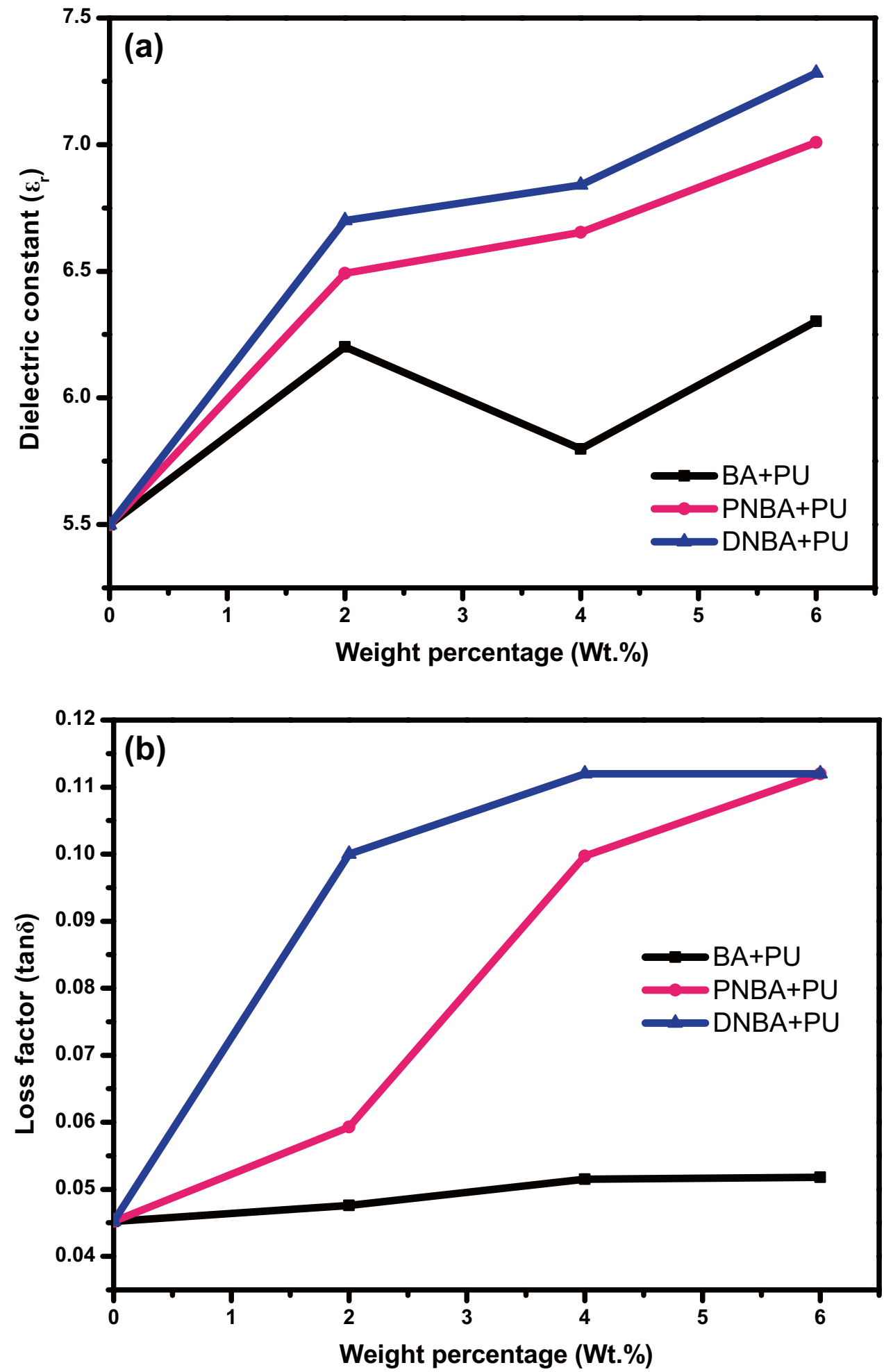

polarization to the system [42-44]. The trend is shown in the graph (Fig. 2(a), (b).

The dielectric loss factor $(\tan \delta)$ for each sample increased very fast between 2 and $4 \%$ then it starts decreasing at $6 \%$ doping content as shown in Fig. 2(b).

\section{DC volume resistivity}

DC volume resistivity ( $\rho$ ) was measured by IM6 MEGOHMMETER from RE setup. The measurement specimens were taken from the $1 \mathrm{~mm}$ thick sheet of prepared samples. The 
measurement was done at a constant room temperature of $23{ }^{\circ} \mathrm{C}$ and DC voltage between electrodes was $500 \mathrm{~V}$. The electrodes diameter and contact area was $7.5 \mathrm{~cm}$ and 44.156 $\mathrm{cm}^{2}$, respectively. The waiting time for the reading of each measurement was $60 \mathrm{~s}$.

As previous studies show this type of polymer can be used in energy harvesting, piezoelectricity, and sensing applications [12] so it would be essential to elucidate static electrical properties as a function of dopants concentration. Therefore, Fig. 3 shows the plot of the variation of DC volume resistivity with the percentage doping content of each sample series. It is observed from Fig. 3 that the undoped polymer shows high electric resistivity of about $10^{12} \Omega-\mathrm{cm}$, which is found consistent with previous studies [42, 44-47]. Also, the inclusion of polar molecules in a nonpolar polymer matrix improves conductivity by reducing the resistivity by several orders of magnitude. These findings support permittivity findings that polar dopants in a polymer system cause an increase in mobility. As a consequence, more obstruction will be created, resulting in a decrease volume resistivity. [45-47]. It also shows that a nitro group in benzoic acid boosts the higher reduction in resistivity. In addition, the volume resistivities measured from 4-nitrobenzoic acid and 3,5-dinitrobenzoic acid series are observed to converge unexpectedly approx. at $5 \mathrm{wt}$. \%. It is also noted, during the measurement of DC resistivity of undoped and doped PUEs the reading was very stable (no fluctuation) as tabulated in Table 3.
Table 3 Volume resistivity measurement results for $1 \mathrm{~mm}$ thick samples

\begin{tabular}{lcl}
\hline Sample Name & $\begin{array}{l}\text { Resistance } \\
(\mathrm{R}, \mathrm{M} \Omega)\end{array}$ & $\begin{array}{l}\text { Volume Resistivity } \\
(\rho, \Omega-\mathrm{cm})\end{array}$ \\
\hline Pure PU & $1.75 \times 10^{3}$ & $7.727 \times 10^{11}$ \\
PU +2\% BA & $0.7 \times 10^{3}$ & $2.943 \times 10^{11}$ \\
PU +4\% BA & $0.32 \times 10^{3}$ & $1.412 \times 10^{11}$ \\
PU +6\% BA & $0.29 \times 10^{3}$ & $1.280 \times 10^{11}$ \\
PU +2\% PNBA & $2.45 \times 10^{2}$ & $1.092 \times 10^{11}$ \\
PU +4\% PNBA & $0.65 \times 10^{2}$ & $2.870 \times 10^{10}$ \\
PU +6\% PNBA & $1.22 \times 10^{1}$ & $5.281 \times 10^{9}$ \\
PU +2\% DNBA & $7.9 \times 10^{1}$ & $3.596 \times 10^{10}$ \\
PU +4\% DNBA & $4.6 \times 10^{1}$ & $1.972 \times 10^{10}$ \\
PU +6\% DNBA & $1.7 \times 10^{1}$ & $7.359 \times 10^{9}$ \\
\hline
\end{tabular}

\section{Effect of doping on thermo-mechanical properties}

\section{Differential scanning calorimetry (DSC)}

DSC823e by METTLER was used for the analysis of the thermal properties of the sample. Figure 4(a) shows the DSC thermogram for pure and doped polyurethane. The graph shows a weak transition at temperature around $-63{ }^{\circ} \mathrm{C}$. The glass transition temperature of soft segment $\left(\mathrm{T}_{\mathrm{g}, \mathrm{ss}}\right)$ is found around $-59{ }^{\circ} \mathrm{C}$. There is no other transition or peaks recorded which clearly indicating the purity of the undoped PUEs sample. Also, a very weak transition is recorded for all the
Fig. 3 Variation of DC volume resistivity with percentage of doping moieties

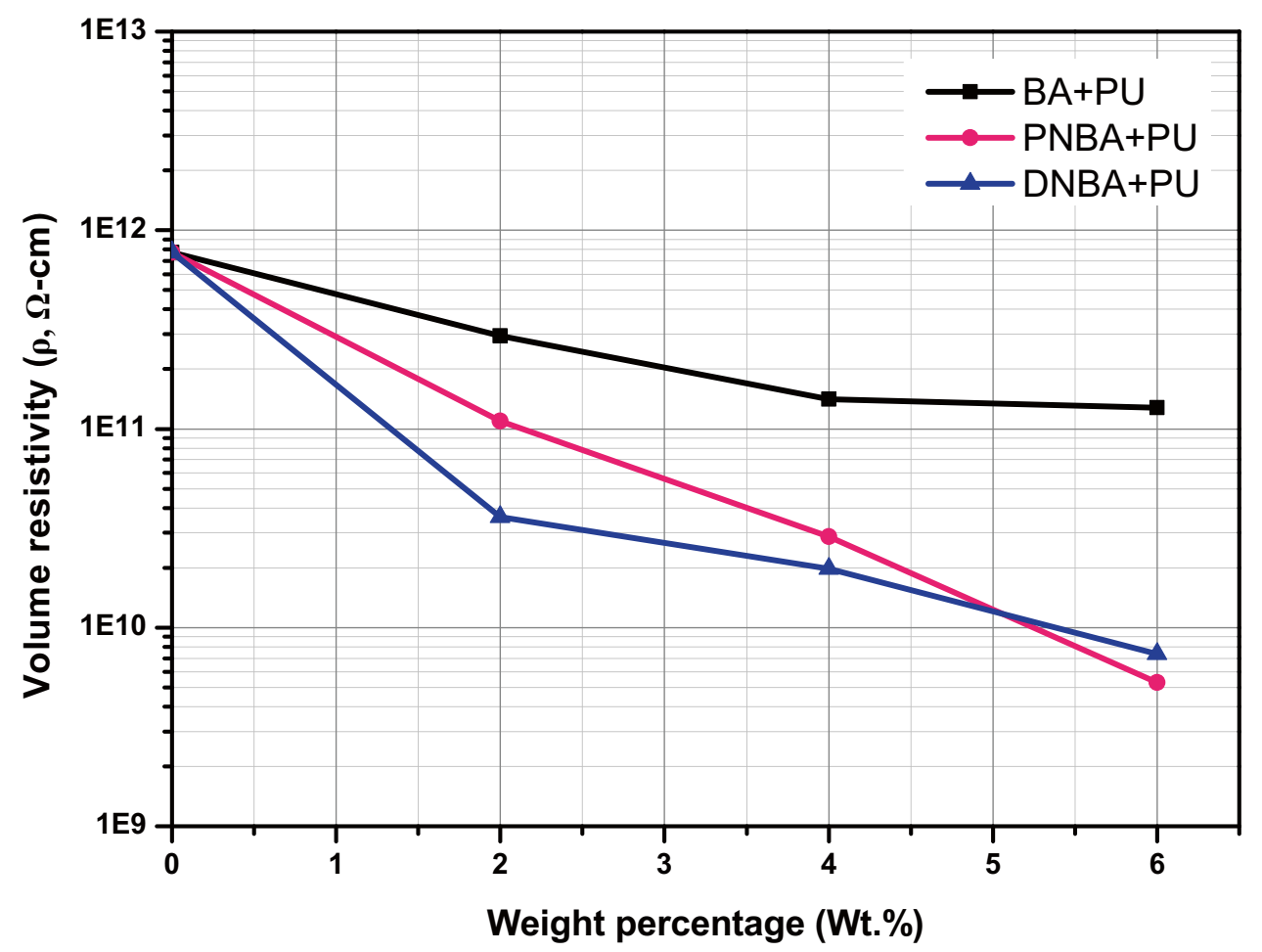



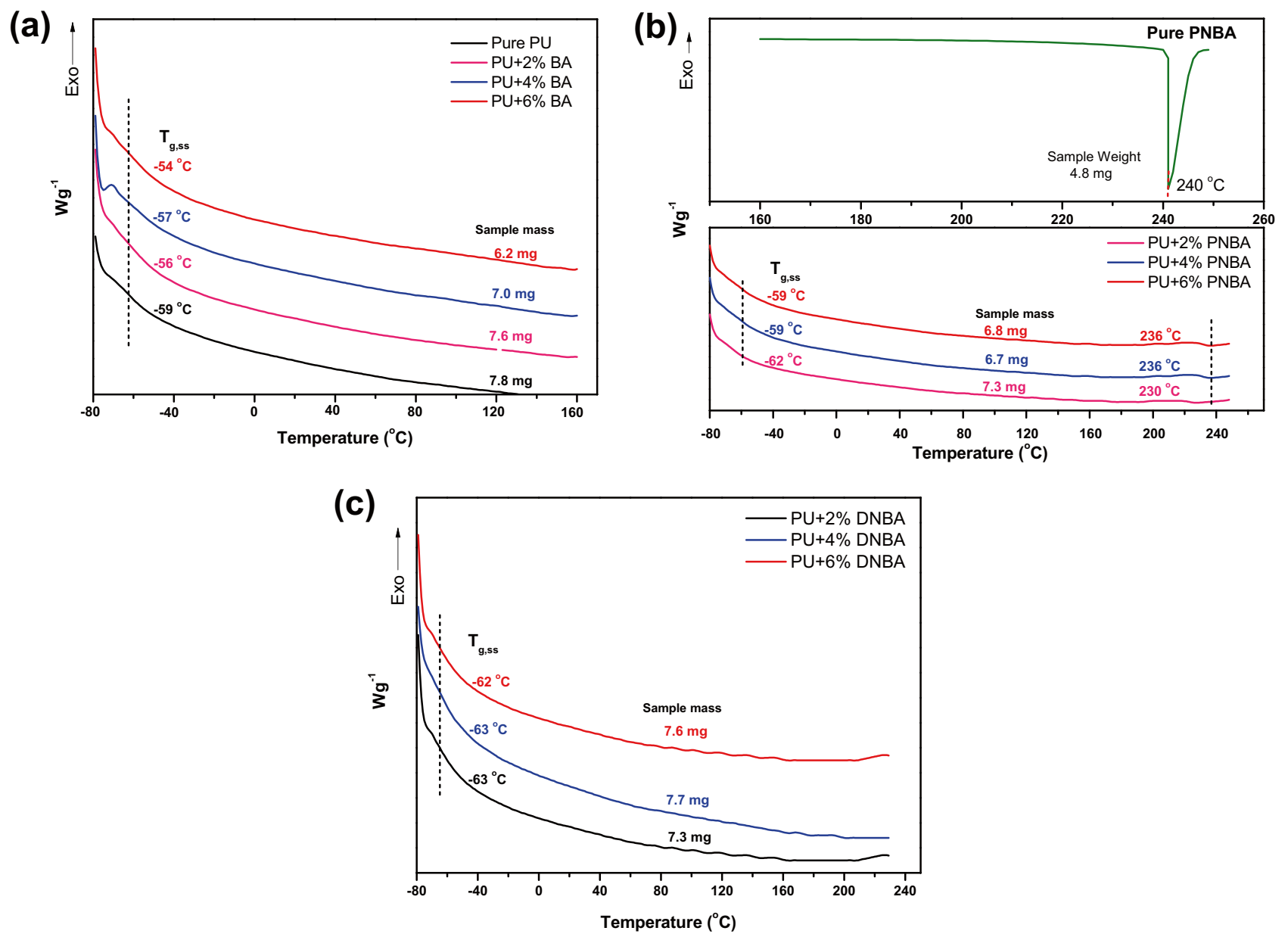

Fig. 4 (a) DSC thermograms for Benzoic acid (BA) doped PU elastomers. (b) DSC thermogram of pure para(4)-nitro-benzoic acid (PNBA) and PNBA doped PU elastomers. (c) DSC thermograms for 3, 5- di-nitro- benzoic acid (DNBA) doped PU elastomers

doped samples which are very similar in trends to the pure one except for some little variation. There is no other transition or peaks seen which clearly indicates doping moieties completely reacted to the PU system. Figure 4(b) is a combined thermogram for pure 4(para)-nitro-benzoic acid (PNBA) and PU doped with PNBA, similar to Fig. 4(a) as very weak transitions are observed with exception of little endothermic peaks at around $230{ }^{\circ} \mathrm{C}, 236^{\circ} \mathrm{C}$, and $236^{\circ} \mathrm{C}$ of $2 \%, 4 \%$ and $6 \%$ wt. $\%$ of PNBA crystals, respectively. Comparing with the thermograph of pure PNBA, this is clear that these peaks did not significantly change but it is still in the range of melting temperature $\left(240{ }^{\circ} \mathrm{C}\right)$ of PNBA. This clearly indicates that the PNBA partially reacted to the PU system, a dispersed phase of PNBA crystals is found in the PU matrix. The reason for partial solubility or insolubility of PNBA crystal in the PU system is maybe due to the presence of moisture (water molecules) in the PART-A materials mixture and PNBA is insoluble in normal or cold water [53].

Figure 4(c) is a DSC plot for 3, 5- di-nitro- benzoic acid (DNBA) doped PU elastomers. Thermogram shows, very weak transitions near to glass transition of PU, and no endothermic peaks were observed. This means the DNBA moieties completely reacted to the PU system. However, the glass transition temperature of the hard segment $\left(\mathrm{T}_{\mathrm{g}, \mathrm{HS}}\right)$, a small transition temperature at a higher temperature, did not observe by the DSC technique because it is not sensitive enough. The $\mathrm{T}_{\mathrm{g}, \mathrm{SS}}$ and $\mathrm{T}_{\mathrm{g}, \mathrm{HS}}$ from the DSC measurement are tabulated in Table 4.

\section{Dynamic mechanical analysis (DMA)}

Dynamic mechanical analysis is used for the measurement of viscoelastic properties. The storage modulus gives information about the stiffness, while the loss tangent $(\tan \delta)$, provides information about the degree of molecular motion. The transition peak in the $\tan \delta$ curve gives the glass transition temperature $\left(\mathrm{T}_{\mathrm{g}}\right)$. The main feature of the smaller areas of low-temperature maximum location on $\tan \delta$ curve is that it is related to the better phase separation of PU soft and hard segment also hard phase incorporation in the glass transition 
Table 4 Thermal properties of pure and doped polyurethane elastomers

\begin{tabular}{|c|c|c|c|c|}
\hline \multirow[t]{2}{*}{ Sample name } & \multicolumn{2}{|l|}{ DSC } & \multicolumn{2}{|l|}{ DMA } \\
\hline & $\mathrm{T}_{\mathrm{g}}, \mathrm{ss} /{ }^{\circ} \mathrm{C}$ & $\mathrm{T}_{\mathrm{g}}$, HS $/{ }^{\circ} \mathrm{C}$ & $\mathrm{T}_{\mathrm{g}}, \mathrm{ss} /{ }^{\circ} \mathrm{C}$ & $\mathrm{T}_{\mathrm{g}}, \mathrm{HS} /{ }^{\circ} \mathrm{C}$ \\
\hline Pure PU & -59 & NA & -48 & -1 \\
\hline $\mathrm{PU}+2 \% \mathrm{BA}$ & -56 & NA & -47 & -3 \\
\hline $\mathrm{PU}+4 \% \mathrm{BA}$ & -57 & NA & -49 & -8 \\
\hline $\mathrm{PU}+6 \% \mathrm{BA}$ & -54 & NA & -44 & -11 \\
\hline $\mathrm{PU}+2 \% \mathrm{PNBA}$ & -62 & NA & -50 & 0 \\
\hline $\mathrm{PU}+4 \% \mathrm{PNBA}$ & -59 & NA & -46 & -7 \\
\hline $\mathrm{PU}+6 \%$ PNBA & -59 & NA & -47 & -4 \\
\hline $\mathrm{PU}+2 \% \mathrm{DNBA}$ & -62 & NA & -50 & 6 \\
\hline $\mathrm{PU}+4 \% \mathrm{DNBA}$ & -63 & NA & -49 & 8 \\
\hline $\mathrm{PU}+6 \% \mathrm{DNBA}$ & -63 & NA & -48 & 0.5 \\
\hline
\end{tabular}

is less. The magnitude of $\tan \delta$ across the application temperature is defined as the ratio of heat energy absorbed by the sample to energy returns as the sample movement [48].

The DMA measurement for each sample in the temperature range $-80{ }^{\circ} \mathrm{C}$ to $-100{ }^{\circ} \mathrm{C}$ was measured with the instrument DMA 8000 Perkin Elmer at the frequency of $1 \mathrm{~Hz}$ and a heating rate of $2{ }^{\circ} \mathrm{C} / \mathrm{min}$. The plots for each sample are shown in Fig. 5, 6, and 7. The storage modulus for all doped samples is very high and constant at a low temperature around $-80{ }^{\circ} \mathrm{C}$ and it starts decreasing from around temperature $-50{ }^{\circ} \mathrm{C}$ to further increase in temperature. The trend of decrease in storage modulus with an increase in temperature is the same for all samples. Furthermore, the magnitude of modulus of all doped samples shows 10 times higher than the pure one except for the $2 \%$ BA doped PU. The $\tan \delta$ curve represents a peak (lower peak) related to the $\mathrm{T}_{\mathrm{g}, \mathrm{SS}}$ at the same temperature range between $-44{ }^{\circ} \mathrm{C}$ and $-50{ }^{\circ} \mathrm{C}$ as tabulated in Table 4 . The intensity of $\tan \delta$ peak of the soft segment for all doped samples tends to decrease as compared to a pure one.

The decrease in intensity of $\tan \delta$ peak of the soft segment for PNBA doped PUE is less than the other two doped samples, this is maybe because PNBA crystals are not completely reacted to the PU chain but it is dispersed. The other reason may be due to PNBA restricted the polyol segment motion in PU structure. At high temperatures, a shift of the $\tan \delta$ curve to higher temperature is noted for all the samples. Result reveals a little shift for PNBA doped PU and also slight broadening and high intensity of the peaks associated with hard segment is noted for all samples but this effect is more for DNBA doped PU. This is maybe because of the rise in the number of larger lengths of hard segment chains in hard domains which contributes to polymer's hard segment content [49-51]. This significant increase in hard segments improves the hard segment crystallinity and phase separation that further reduces the mobility of the soft segment [49].

\section{Thermal conductivity}

TCi thermal conductivity analyzer (C-THERM) was used to measure the thermal conductivity of the pure and doped samples. For measurements, the sample is placed on the
Fig. 5 (a) and (b) shows storage modulus and tan $\delta$ from DMA of pure and benzoic acid (BA) doped PU elastomer
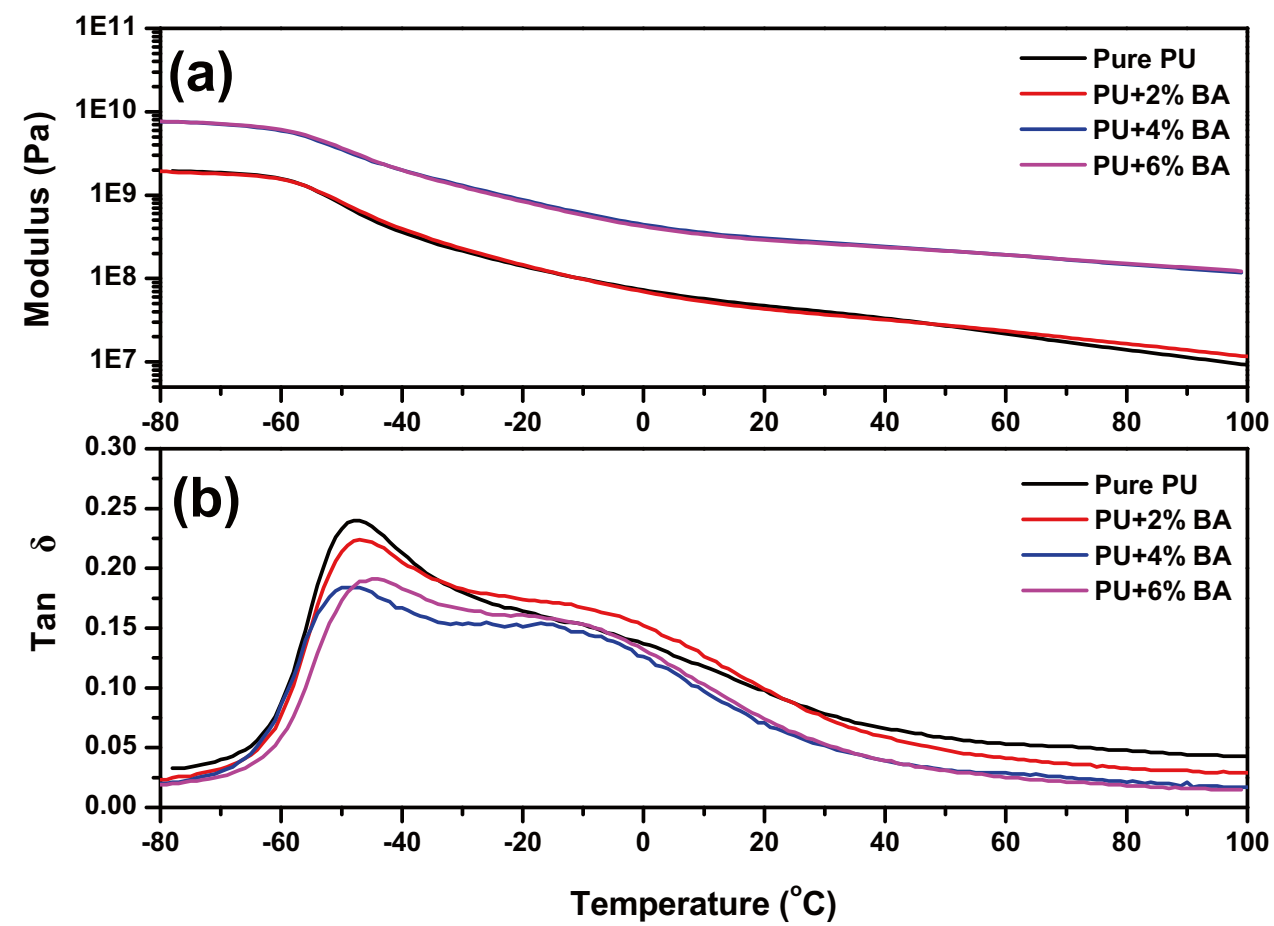
Fig. 6 (a) and (b) shows storage modulus and tan $\delta$ from DMA of pure and 4(p)-nitro-benzoic acid (PNBA) doped PU elastomer

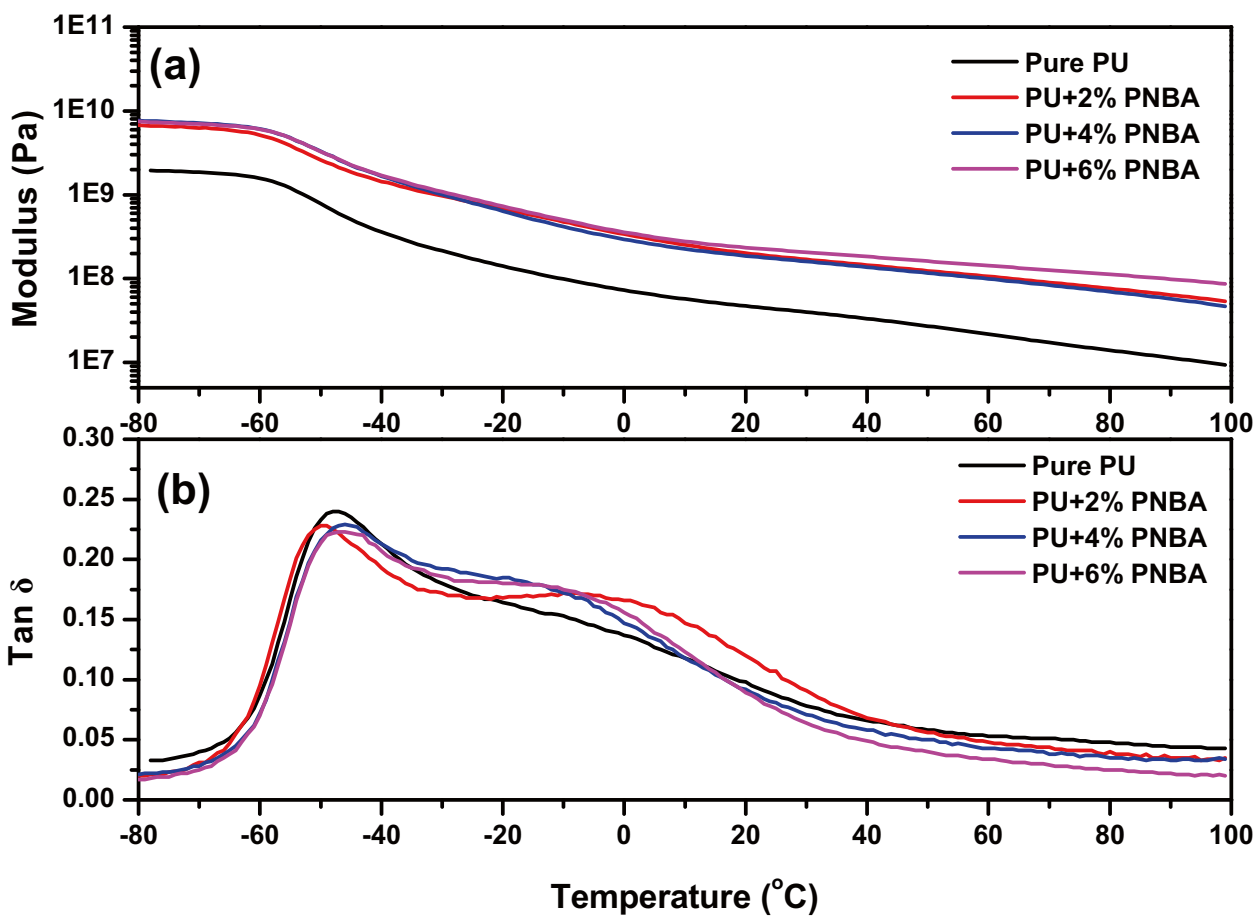

sensor at room temperature and a small amount of heat generated by applying a current of known amplitude to a heating element (spiral) of the sensor is applied. The thermophysical characteristics are inversely proportional to the rate at which the sensor voltage increases [48]. Figure 8 shows the variation of thermal conductivity of pure and BA, PNBA, and DNBA doped PUE with different doping contents. The result of BA doped PUE shows a different trend as compared to PNBA and DNBA doped samples. This variation may be because BA has no nitro group and it reacted to the PU backbone differently. On average thermal conductivity is constant except for little variation as tabulated in Table 5. The variation of thermal conductivity due to PNBA and DNBA is following the same trend and an increase of the nitro group
Fig. 7 (a) and (b) shows storage modulus and $\tan \delta$ from DMA of pure and 3, 5 di-nitro- benzoic acid (DNBA) doped PU elastomer

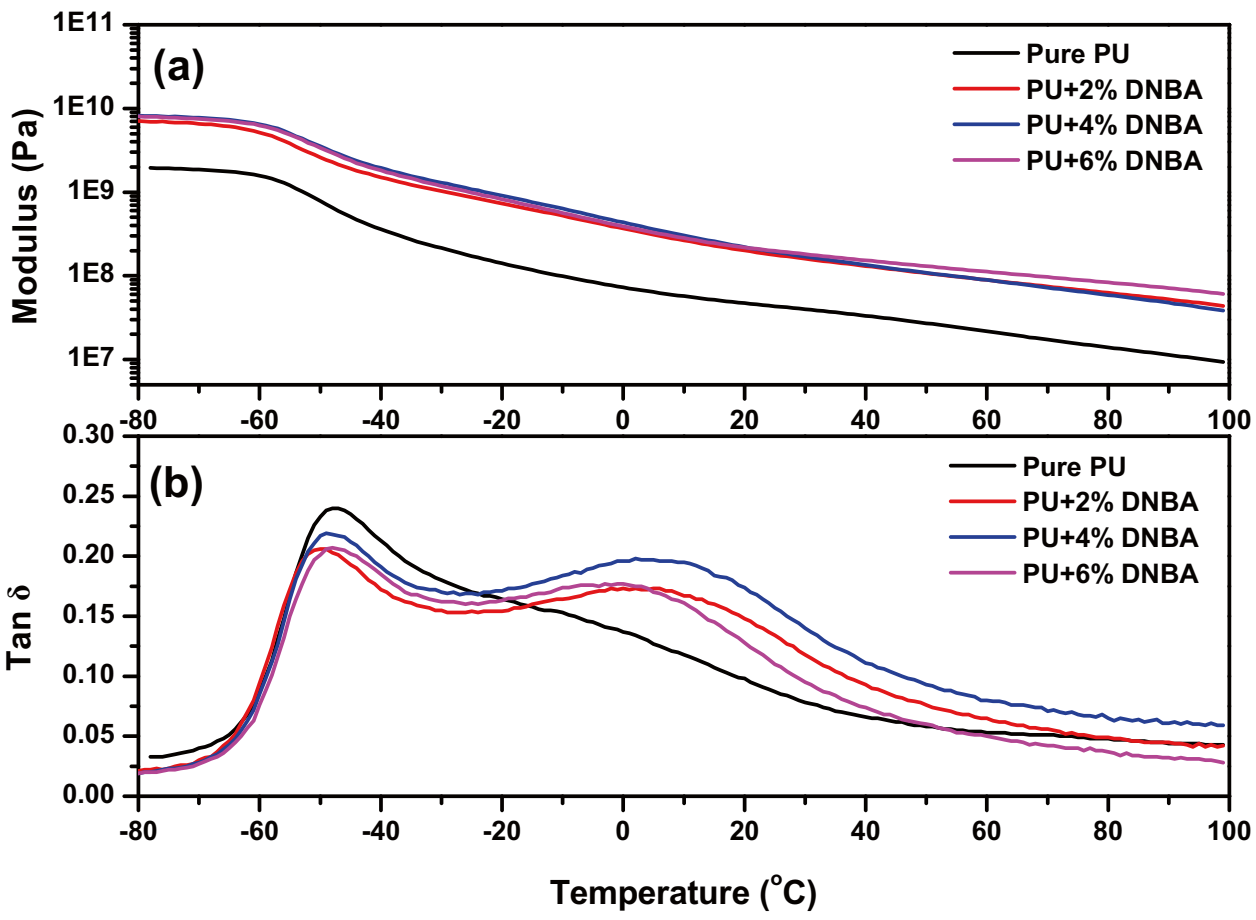


Fig. 8 Thermal conductivity of pure and BA, PNBA, and DNBA doped PU Elastomers

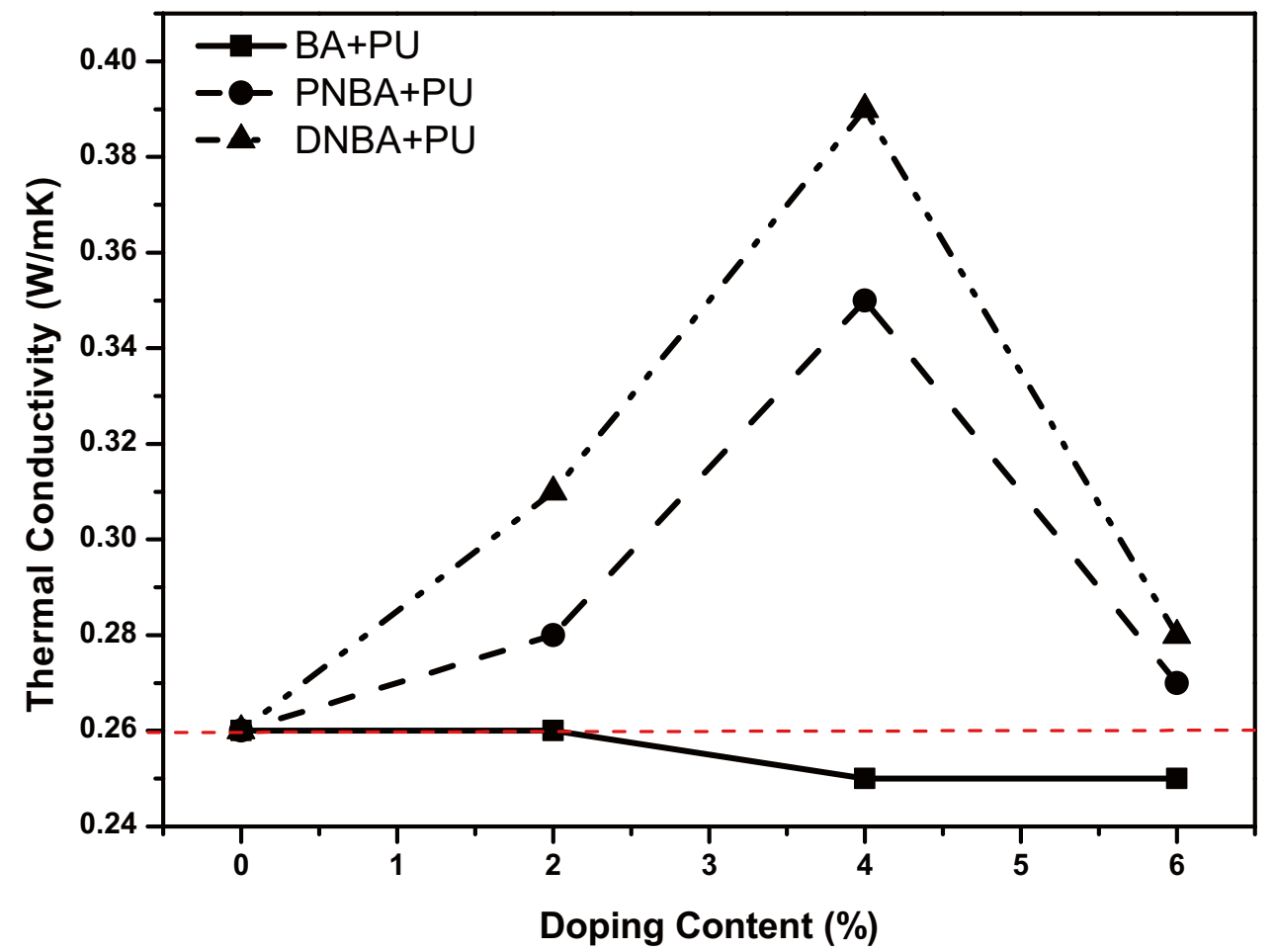

in doping moieties increases the thermal conductivity. For PNBA and DNBA doped samples it is increased up to $4 \%$ doping content and then it ramps down at $6 \%$ doping content. This increase thermal conductivity might be due to increasing the ordering of molecular chains (crystallinity) level by cross-linking when doping content was increased but higher doping (up to 6\%) led to lower crystallinity and hence lower thermal conductivity. Moreover, it may be because thermal conductivity is strongly dependent on polymer crystallinity. The physical properties are also heavily affected by the hard segment content of polyurethane [52]. The maximum thermal conductivity is found for DNBA doped PU which is about $0.39 \mathrm{Wm}^{-1} \mathrm{~K}^{-1}$ at $4 \%$ content.

Table 5 Thermal conductivity of pure and doped polyurethane elastomers

\begin{tabular}{ll}
\hline Doping Content $(\%)$ & $\begin{array}{l}\text { Thermal } \\
\text { conductivity } \\
\left(\mathrm{Wm}^{-1} \mathrm{~K}^{-1}\right)\end{array}$ \\
\hline Pure PU & 0.26 \\
PU +2\% BA & 0.26 \\
PU +4\% BA & 0.25 \\
PU +6\% BA & 0.25 \\
PU +2\% PNBA & 0.26 \\
PU +4\% PNBA & 0.28 \\
PU +6\% PNBA & 0.35 \\
PU +2\% DNBA & 0.31 \\
PU +4\% DNBA & 0.39 \\
PU +6\% DNBA & 0.28 \\
\hline
\end{tabular}

\section{Conclusions}

Pure and doped PU elastomers with three different weight percentage $2 \%, 4 \%$, and $6 \%$ of each doping moieties namely benzoic acid (BA), 4(p)-nitro-benzoic acid (PNBA), and 3, 5-di-nitro-benzoic acid (DNBA) were successfully prepared using the solution casting method. Electrical DC volume resistivity measurement showed a high electric resistivity of about $10^{12} \Omega$-cm for the pure-PU sample and a decrease in the resistivity for each type of doping agent. This confirms the fact that a polar molecule in a nonpolar polymer matrix improves conductivity. The dielectric constant of pure PU is found less than the doped ones this is due to the contribution of dipole polarization in addition to electronic polarization to the polymer. DSC thermograms of doped PUE represented a very weak transition near Tg,ss and no other endothermic peaks as compared to the Pure PU except for PNBA doped PUE. This is confirming that all doping molecules (BA and DNBA) completely reacted to the system except for the PNBA crystals. DMA results showed the magnitude of modulus of all doped samples were approx. 10 times higher than the pure one except for the $2 \% \mathrm{BA}$ doped PU. The intensity of $\tan \delta$ peak of the soft segment for all doped samples tends to decrease as compared to a pure one, this decrease for PNBA doped PUE is less than the other two doped samples. Increasing in the number of higher lengths of the hard segment chains in hard domains that occur as the hard segment content of the polymer can be approved from a little shift for PNBA doped PUE and 
also slight broadening and high intensity of the peaks associated with hard segment was noted for all samples but this effect is more for DNBA doped PUE. The nitro group in the doping moieties greatly affects the thermal conductivity. This variation may be because BA has no nitro group and it reacted to the PU backbone differently when compared to PNBA and DNBA doped samples. The maximum thermal conductivity is found for DNBA doped PUE which is about $0.39 \mathrm{~W} \mathrm{~m}^{-1} \mathrm{~K}^{-1}$ at $4 \%$ content.

Supplementary Information The online version contains supplementary material available at https://doi.org/10.1007/s10965-021-02538-6.

Acknowledgments The authors are thankful to the Institute of Ceramic and Polymer Engineering, University of Miskolc, and Polyurethane and PVC laboratories of BorsodChem Zrt. for valuable scientific and technical assistance.

\section{Funding Open access funding provided by University of Miskolc}

Open Access This article is licensed under a Creative Commons Attribution 4.0 International License, which permits use, sharing, adaptation, distribution and reproduction in any medium or format, as long as you give appropriate credit to the original author(s) and the source, provide a link to the Creative Commons licence, and indicate if changes were made. The images or other third party material in this article are included in the article's Creative Commons licence, unless indicated otherwise in a credit line to the material. If material is not included in the article's Creative Commons licence and your intended use is not permitted by statutory regulation or exceeds the permitted use, you will need to obtain permission directly from the copyright holder. To view a copy of this licence, visit http://creativecommons.org/licenses/by/4.0/.

\section{References}

1. Akindoyo JO, Beg M, Ghazali S, Islam MR, Jeyaratnam N, Yuvaraj AR (2016) Polyurethane types, synthesis and applications-a review. RSC Adv 6(115):114453-114482

2. Ghosh S, Ganguly S, Remanan S, Mondal S, Jana S, Maji PK, Das NC (2018) Ultra-light weight, water durable and flexible highly electrical conductive polyurethane foam for superior electromagnetic interference shielding materials. J Mater Sci: Mater Electron 29(12):10177-10189

3. Jaganathan SK, Mani MP, Palaniappan SK, Rathanasamy R (2018) Fabrication and characterisation of nanofibrous polyurethane scaffold incorporated with corn and neem oil using single stage electrospinning technique for bone tissue engineering applications. J Polym Res 25(7):1-12

4. Petroff CA, Bina TF, Hutchison GR (2019) Highly tunable molecularly doped flexible poly (dimethylsiloxane) foam piezoelectric energy harvesters. ACS Applied Energy Materials 2(9):6484-6489

5. Zhang Y, Bowen CR, Deville S (2019) Ice-templated poly (vinylidene fluoride) ferroelectrets. Soft Matter 15(5):825-832

6. Tolvanen J, Hannu J, Nelo M, Juuti J, Jantunen H (2016) Dielectric properties of novel polyurethane-PZT-graphite foam composites. Smart Mater Struct 25(9):095039

7. Hamdi O, Mighri F, Rodrigue D (2018) Piezoelectric cellular polymer films: Fabrication, properties and applications. AIMS Mater Sci 5:845
8. Maceiras A, Martins P, Gonçalves R, Botelho G, Ramana EV, Mendiratta SK, León LM (2015) High-temperature polymer based magnetoelectric nanocomposites. Eur Polymer J 64:224-228

9. Chien CC, Hsu Y, Lee CK, Tang WC (2020) Analysis and development of a ferroelectret cellular PP film. In Behavior and Mechanics of Multifunctional Materials IX, 11377 (113770J). Intern Soc Optics Photo.

10. Moody MJ, Marvin CW, Hutchison GR (2016) Molecularlydoped polyurethane foams with massive piezoelectric response. Journal of Materials Chemistry C 4(20):4387-4392

11. Mishra S, Unnikrishnan L, Nayak SK, Mohanty S (2019) Advances in piezoelectric polymer composites for energy harvesting applications: a systematic review. Macromol Mater Eng 304(1): 1800463

12. Safaei M, Sodano HA, Anton SR (2019) A review of energy harvesting using piezoelectric materials: state-of-the-art a decade later (2008-2018). Smart Mater Struct 28(11):113001

13. Saxena P, Shukla P (2020) A Review of Polymer Electrets and Their Applications. Materials Performance and Characterization 9(1):701-710

14. Hassan T, Salam A, Khan A, Khan SU, Khanzada H, Wasim M, Kim IS (2021) Functional nanocomposites and their potential applications: A review. J Polym Res 28(2):1-22

15. Ramadan KS, Sameoto D, Evoy S (2014) A review of piezoelectric polymers as functional materials for electromechanical transducers. Smart Mater Struct 23(3):033001

16. Gilmanov IR, Galikhanov MF, Gilmanova AR (2017). Interrelation of electret properties of polyethylene foam from the method of cross-linking. In AIP Conference Proceedings 1886 (1), 020079. AIP Publishing LLC.

17. Zegaoui A, Derradji M, Medjahed A, Dayo AQ, Dong W, Liu WB, Liu YG (2018) Multifunctional polymer materials with enhanced mechanical, thermal and gamma radiation shielding properties from dicyanate ester of bisphenol-A/bisphenol-A based benzoxazine resin and short kevlar/basalt hybrid fibers. J Polym Res 25(12):1-13

18. Liu F, Zhai Z, Shi WJ, Feng LX, Wang Z, Qin G, Li Z (2021) Rational enhancement of electro-optic activity: Design and synthesis of cyanoacetate containing nonlinear optical chromophores. Dyes Pigm 185:108914

19. Kalinin AA, Islamova LN, Shmelev AG, Fazleeva GM, Fominykh OD, Dudkina YB, Balakina MY (2021) D- $\pi$-A chromophores with a quinoxaline core in the $\pi$-bridge and bulky aryl groups in the acceptor: Synthesis, properties, and femtosecond nonlinear optical activity of the chromophore/PMMA guest-host materials. Dyes Pigm 184:108801

20. Abomostafa, H. M., \& Abulyazied, D. E. (2021). Linear and Nonlinear Optical Response of Nickel Core-Shell@ Silica/ PMMA Nanocomposite Film for Flexible Optoelectronic Applications. J Inorganic Organometal Polym Mater, 1-13.

21. Shelkovnikov VV, Vasil'ev, E. V., Vasil'eva, N. V., Korotaev, S. V., Kargapolova, I. Y., \& Orlova, N. A. (2020) Determining Poling Conditions of Chromophore-Polymer Films in the Field of Corona Discharge by Measuring Signal of Generation of Second Harmonic. Optoelectronics, Instrumentation and Data Processing 56(4):398-404

22. Mukhtarov A, Smirnov M, Balakina M, Vakhonina T (2020) The study of dipolar relaxation in chromophore-containing methacrylic copolymers using thermally stimulated depolarization current measurements. In AIP Conference Proceedings, 2308(1), 030016. AIP Publishing LLC.

23. Thomson G, Lai Z, Val DV, Yurchenko D (2019) Advantages of nonlinear energy harvesting with dielectric elastomers. J Sound Vib 442:167-182 
24. Balakina MY (2007) Pyro-and piezoelectric effects in nonlinear optical polymer electrets: New theoretical models. J Non-Cryst Solids 353(47-51):4432-4436

25. Smirnov M, Mukhtarov AS, Ivanova NV, Vakhonina TA, Semashko VV, Balakina MY (2014) The effect of chromophores concentration on the nonlinear optical activity of methacrylic copolymers with azochromophores in the side chain. In Journal of Physics: Conference Series, 560(1), 012015. IOP Publishing.

26. Shelton AH, Price RS, Brokmann L, Dettlaff B, Schanze KS (2013) High efficiency platinum acetylide nonlinear absorption chromophores covalently linked to poly (methyl methacrylate). ACS Appl Mater Interfaces 5(16):7867-7874

27. Wang LD, Tong L, Wu JW, Zhang QR, Zhang T (2021) Synthesis of polyurethane-imids and application in surface plasmon polaritons waveguide. Appl Phys A 127(1):1-11

28. Wang LD, Tang J, Li RZ, Zhang T, Tong L, Tang J, Xu L (2017) Synthesis and characterization of electro-optic polyurethaneimide and fabrication of optical waveguide device. High Perform Polym 29(8):879-888

29. Wang LD, Tong L, Sun HY, Tang J, Zhang T (2018) Synthesis and characterization of electro-optic waveguide material polyurethaneimides. J Polym Res 25(2):1-8

30. Lee JY, Kim JH, Jung WT, Park YK (2007) Synthesis and nonlinear optical properties of novel Y-type polyurethanes with high thermal stability of dipole alignment. J Mater Sci 42(11):3936-3943

31. Tasaganva RG, Kariduraganavar MY, Inamdar SR (2009) Synthesis and nonlinear optical properties of polyurethanes containing nitro-substituted 1, 3, 4-oxadiazole chromophores. Synth Met 159(17-18):1812-1819

32. Kariduraganavar MY, Tambe SM, Tasaganva RG, Kittur AA, Kulkarni SS, Inamdar SR (2011) Studies on nonlinear optical polyurethanes containing heterocyclic chromophores. J Mol Struct 987(1-3):158-165

33. No HJ, Cho YJ, Lee JY (2010) Synthesis and Nonlinear Optical Properties of Novel Y-Type Polyurethane Containing Cyanovinylthiazole. Mol Cryst Liq Cryst 520(1):179-455

34. No HJ, Jang HN, Jin Cho Y, Lee JY (2010) Synthesis and nonlinear optical properties of novel Y-type polyurethane containing tricyanovinylthiazole with enhanced thermal stability of second harmonic generation. J Polym Sci, Part A: Polym Chem 48(5):1166-1172

35. Nadafan M, Malekfar R, Dehghani Z (2015) Microstructural and nonlinear optical properties of $\mathrm{SiO} 2$ and $\mathrm{Al} 2 \mathrm{O} 3$ nanoparticles doped in polyurethane. J Mater Res 30(11):1788

36. Nadafan M, Dehghani Z, Fakhrinia SI (2016) Synthesis and nonlinear optical studies of organometallic Cobalt (II) with polyurethane elastomer. Optik 127(20):9361-9366

37. Nadafan M, Malekfar R, Dehghani Z (2017) The Third Order Nonlinear Optical behavior of Poly Ether Urethane. Journal of Interfaces, Thin Films and Low dimensional systems 1(1):23-28

38. Nadafan M, Anvari JZ (2020) Evaluation of structural, optical and physical properties of polyurethane composites doped with metal alkoxides. Mater Sci-Pol 38(3):416-423

39. Lee JY, Bang HB, Park EJ, Baek CS, Rhee BK, Lee SM (2004) Synthesis and nonlinear optical properties of novel polyurethanes with high thermal stability of dipole alignment. Synth Met 144(2):159-167
40. Lee JY, Bang HB (2004) Molecular design, synthesis and properties of novel polyurethanes containing tetracyanocyclopropyl groups as piezoelectric chromophores. Macromol Chem Phys 205(1):101-106

41. Dong S, Yu G, Li Z, Liu Y, Ye C, Qin J (2007) Novel secondorder nonlinear optical main-chain polyurethanes: Adjustable subtle structure, improved thermal stability and enhanced nonlinear optical property. Polymer 48(19):5520-5529

42. Oprea S, Potolinca VO, Oprea V (2021) New polyurethanes with specific dielectric behavior through included of 1,3, 4-thiadiazole derivative in their structure. Eur Polymer J 143:110177

43. Alwaan IM, Hassan A, Piah MAM (2015) Effect of zinc borate on mechanical and dielectric properties of metallocene linear lowdensity polyethylene/rubbers/magnesium oxide composite for wire and cable applications. Iran Polym J 24(4):279-288

44. Xiang D, Liu M, Chen G, Zhang T, Liu L, Liang Y (2017) Optimization of mechanical and dielectric properties of poly (urethaneurea)-based dielectric elastomers via the control of microstructure. RSC Adv 7(88):55610-55619

45. Mizera K, Auguści M, Woronka D, Liper K, Kalarus W, Ryszkowska J (2016) Polyurethane composites with mixture of carbon fibers and glass frit. Polimery, 61.

46. Kowalczyk K, Kugler S, Spychaj T (2014) Antistatic polyurethane coats with hybrid carbon nanofillers. Polimery 59(9):650-655

47. Cruz SM, Viana JC (2015) Melt blending and characterization of carbon nanoparticles-filled thermoplastic polyurethane elastomers. J Elastomers Plast 47(7):647-665

48. Somdee P, Lassú-Kuknyó T, Kónya C, Szabó T, Marossy K (2019) Thermal analysis of polyurethane elastomers matrix with different chain extender contents for thermal conductive application. J Therm Anal Calorim 138(2):1003-1010

49. Somdee P, Lassú-Kuknyó T, Kónya C, Ibrahim JF, Marossy K (2020). Investigation of the rubber elasticity and properties of polyurethane elastomers with different silicon carbide contents. In Journal of Physics: Conference Series, 1527(1), 012038. IOP Publishing.

50. Hazmi ASA, Pauzi NNPN, Maurad ZA, Abdullah LC, Aung MM, Ahmad A, Saniman SE (2017) Understanding intrinsic plasticizer in vegetable oil-based polyurethane elastomer as enhanced biomaterial. J Therm Anal Calorim 130(2):919-933

51. Rogulska M, Kultys A, Lubczak J (2015) New thermoplastic polyurethane elastomers based on aliphatic-aromatic chain extenders with different content of sulfur atoms. J Therm Anal Calorim 121(1):397-410

52. Wondu E, Lule Z, Kim J (2019) Thermal conductivity and mechanical properties of thermoplastic polyurethane-/silanemodified A12O3 composite fabricated via melt compounding. Polymers 11(7):1103

53. O'Neill MJ (2006) The Merck Index. An Encyclopedia of Chemicals, Drugs and Biologicals. Whitehouse Station, New Jersey: Merck Research Laboratories, Division of Merck and Co.

Publisher's Note Springer Nature remains neutral with regard to jurisdictional claims in published maps and institutional affiliations. 